\title{
Nodular goiter and hyperplastic lesion of the thyroid share common deregulated expression profiles
}

\author{
Ohoud Subhi', Nadia Baqtian', Manar Ata', Sajjad Karim, Khalid Al-Ghamdi², Osman Abdel Al-Hamour ${ }^{3}$, \\ Mohammed Hussein Al-Qahtani ${ }^{1}$, Hans-Juergen Schulten ${ }^{1 *}$, Jaudah Al-Maghrabi ${ }^{4,5}$
}

From 2nd International Genomic Medical Conference (IGMC 2013)

Jeddah, Kingdom of Saudi Arabia. 24-27 November 2013

\section{Background}

Proliferative thyroid lesions including nodular goiter and hyperplastic lesion are very common in the Middle East and North African (MENA) region [1]. Hyperplastic lesions are also regarded as a subcategory of goiter. High-density expression profiles in these benign thyroid lesions are not surveyed in detail [2]. In an effort to establish gene expression profiles that distinguish both lesions from each other and from normal thyroid (TN) tissue, we employed state-of-the-art oligonucleotide microarray technology.

\section{Materials and methods}

Whole transcript expression profiles were generated in 17 goiters, 14 hyperplastic lesions and 7 TN samples utilizing Affymetrix HuGene 1.0 ST arrays. We used the default analysis method for generating a threshold of significance for differential expression ( $\mathrm{p}$-value with a false discovery rate $\leq 0.05$ and a fold change $>2$ ). Partek Genomics Suite and Ingenuity Pathway Analysis software packages were utilized to interpret data sets.

\section{Results}

Expression profiles of goiters and hyperplastic lesions were highly related and no transcripts were differentially expressed between these two thyroid lesions under the given statistical threshold values. However, more than 10000 genes were differentially expressed between goiters, as well as hyperplastic lesions, and TN samples. The most differentially expressed transcripts were in fact

\footnotetext{
* Correspondence: hschulten@kau.edu.sa

${ }^{1}$ Center of Excellence in Genomic Medicine Research, King Abdulaziz

University, Jeddah, Kingdom of Saudi Arabia

Full list of author information is available at the end of the article
}

downregulated in both thyroid lesions in comparison to TN samples and include genes like olfactory receptor, family 6 , subfamily $\mathrm{N}$ (OR6N2), glial cells missing homo$\log 1$, Drosophila (GCM1), family with sequence similarity 138, member B (FAM138B), prostate-specific P704P mRNA (P704P), and olfactory receptor, family 5 , subfamily $\mathrm{H}$, member 14 (OR5H14). The most upregulated transcripts in goiters and hyperplastic lesions vs TN samples include genes as cytochrome c oxidase assembly protein COX15 homolog (COX15), dyskeratosis congenita 1, dyskerin (DKC1), and DnaJ (Hsp40) homolog, subfamily A, member 2 (DNAJA2). Networks which were most deregulated in goiter and hyperplastic lesion in comparison to TN tissue share similar functions although certain pathways seem to be differentially affected in both thyroid lesions.

\section{Conclusions}

Our study indicates that goiter and hyperplastic lesion share common deregulated expression profiles in comparison to TN tissue. As a certain number of goiters and hyperplastic lesions bear the capacity to develop to thyroid neoplasms, knowledge of deregulated genes in these lesions may help to identify patients which are at elevated risk for developing thyroid carcinoma. Further studies have to reveal which expression signatures in these benign thyroid lesions are in common with malignant cases.

This study was supported by King Abdulaziz City for Science and Technology (KACST) grants 09-BIO707-03 and 09-BIO820-03. 


\section{Authors' details}

${ }^{1}$ Center of Excellence in Genomic Medicine Research, King Abdulaziz University, Jeddah, Kingdom of Saudi Arabia. ${ }^{2}$ Department of Surgery, Faculty of Medicine, King Abdulaziz University, Jeddah, Kingdom of Saudi Arabia. ${ }^{3}$ Department of Surgery, King Faisal Specialist Hospital and Research Center, Jeddah, Kingdom of Saudi Arabia. ${ }^{4}$ Department of Pathology, Faculty of Medicine, King Abdulaziz University, Jeddah, Kingdom of Saudi Arabia.

${ }^{5}$ Department of Pathology, King Faisal Specialist Hospital and Research Center, Jeddah, Kingdom of Saudi Arabia.

Published: 2 April 2014

\section{References}

1. Schulten HJ, Salama S, Al-Ahmadi A, Al-Mansouri Z, Mirza Z, Al-Ghamdi K, Al-Hamour OA, Huwait E, Gari M, Al-Qahtani MH, et al: Comprehensive Survey of HRAS, KRAS, and NRAS Mutations in Proliferative Thyroid Lesions from An Ethnically Diverse Population. Anticancer Res 2013, 33:4779-4784.

2. Griffith OL, Melck A, Jones SJ, Wiseman SM: Meta-analysis and metareview of thyroid cancer gene expression profiling studies identifies important diagnostic biomarkers. J Clin Oncol 2006, 24:5043-5051.

doi:10.1186/1471-2164-15-S2-P70

Cite this article as: Subhi et al: Nodular goiter and hyperplastic lesion of the thyroid share common deregulated expression profiles. BMC Genomics 2014 15(Suppl 2):P70.

\section{Submit your next manuscript to BioMed Central and take full advantage of:}

- Convenient online submission

- Thorough peer review

- No space constraints or color figure charges

- Immediate publication on acceptance

- Inclusion in PubMed, CAS, Scopus and Google Scholar

- Research which is freely available for redistribution

Submit your manuscript at www.biomedcentral.com/submit 